\title{
Emergencies in Sports Medicine
}

Editors: Julian Redhead and Jonathan Gordon.

Bibliographic Data: ISBN: 978-0-19-960267-4; 2012 by OXFORD University Press Inc., New York, USA, 327 pages, paperback, $\$ 52.75$.

Subjects: Sports Medicine, Emergencies.

Description: Emergencies in Sports Medicine is the ideal book for any doctor to keep in their kit-bag or locker. This essential easy-to-use guide covers all aspects of the emergencies likely to be encountered and gives important information as to their immediate treatment.

Purpose: The goal of the book, as stated in the preface, is that this book should be viewed as an accompaniment to the courses that are available for healthcare professionals to acquire and practice their skills and to provide immediate access to reliable information at the patients' side.

Audience: The book appeals to a wide audience, from the doctor involved directly in sports medicine, to the doctor who is a spectator. It will also appeal to allied health professionals involved in any aspect of sport.

Features: The book is composed of 22 chapters and includes several illustrative tables and figures. The following topics are addressed in the chapters: Chapter 1 is
"Planning and preparation", Chapter 2 is "General approach to the injured or unwell athlete", Chapter 3 is "Cardio-respiratory arrest", Chapter 4 is "Athletes with pre-existing conditions", Chapter 5 is "Collapse during exercise", Chapter 6 is "Altitude sickness", Chapter 7 is "Sudden cardiac death in sport", Chapter 8 is "General medical emergencies", Chapter 9 is "Head injuries", Chapter 10 is "Airway injuries", Chapter 11 is "Maxillofacial injuries and infection in sports medicine", Chapter 12 is "Spinal injuries", Chapter 13 is "Thorax", Chapter 14 is "The abdomen", Chapter 15 is "Pelvic trauma", Chapter 16 is "Upper limb injury", Chapter 17 is "Lower limb injury", Chapter 18 is "Paediatrics", Chapter 19 is "Athletes with a disability", Chapter 20 is "Aggressive patients", Chapter 21 is "Breaking bad news", and Chapter 22 is "Communication".

Assessment: The editors and contributors to this book are highly knowledgeable emergency medical doctors with vast experience in sports medicine emergencies. This guide covers every type of sporting emergency from head injuries to altitude sickness, and provides guidance on the immediate care of patients with these sporting injuries.

Reviewed by: Ufuk Sekir, MD, Assoc. Prof., Department of Sports Medicine, Medical School of Uludag University, Bursa, Turkey 